\title{
INCIDENCIA DE ENMIENDAS CONSTITUCIONALES EN LA AUDITARÍA A LA GESTIÓN DE LAS ORGANIZACIONES PÚBLICAS ECUATORIANAS
}

\section{INCIDENCE OF CONSTITUTIONAL AMENDMENTS ON THE AUDIT OF THE MANAGEMENT OF ECUADORIAN PUBLIC ORGANIZATIONS}

\author{
Pablo Domingo Vilela Mera ${ }^{1}$ \\ Elizabeth Jacqueline Govea Robinzón² \\ Gabriela Elizabeth Vilela Govea ${ }^{3}$
}

Recibido: 2021-05-05/ Revisado: 2021-06-04 / Aceptado: 2021-07-10 / Publicado: 2021-09-15

Forma sugerida de citar: Vilela-Mera, P. D., Govea-Robinzón, E. J. y Vilela-Govea, G. E. (2021). Incidencia de enmiendas constitucionales en la auditaría a la gestión de las organizaciones públicas ecuatorianas. Retos de la Ciencia. 5(e). 87-102. https://doi.org/10.53877/rc.5.e.20210915.08

\section{RESUMEN}

La auditoría de gestión en el sector público, examina las actividades de sus entidades a través de procesos que valoran el uso eficiente, efectivo y eficaz de sus recursos, informando sus resultados con recomendaciones para la toma de decisiones; acción que según la Constitución de 2008, pertenece a la Contraloría según los Art. 211 y 212, que fueron enmendados por la Asamblea en 2015, eliminándole esta función, para evitar duplicidad de trabajos entre organismos, lo que se convirtió en el problema de esta investigación y el objetivo fue conocer sus incidencias, pese a que en 2018 la Corte Constitucional con sentencia No 18 declaró su inconstitucionalidad, publicada en 2019. La metodología consistió en organizar los materiales según el objetivo del trabajo y se los clasificó por fuentes y documentos requeridos, considerando su pertinencia, exhaustividad y actualidad; los métodos utilizados fueron: inductivodeductivo, histórico-lógico y analítico-sintético para comprender sus causas y determinar sus incidencias, teorizado con investigación bibliográfica. El impacto legal negativo en las funciones de control por efecto de las enmiendas es el resultado del

\footnotetext{
${ }^{1}$ Doctor en Ciencias Contables y Financieras (Ph.D). Universidad Técnica "Luis Vargas Torres". Ecuador. E-mail: pd_vilela@hotmail.com / ORCID: https://orcid.org/0000-0002-4179-8181

2 Doctora en Ciencias Contables y Financieras (Ph.D). Universidad Técnica "Luis Vargas Torres". Ecuador. E-mail: yaqui-63@hotmail.com / ORCID: https://orcid.org/0000-0002-4502-8264

3 Magíster en Economía con énfasis en Administración de Empresa. Escuela Superior Politécnica del Litoral. Ecuador. E-mail: gababu-85@hotmail.com / ORCID: https://orcid.org/0000-0002-1480-1680
} 
trabajo, dejándose de realizar 247 exámenes en ese período; discusión que demandó mayor control a la gestión, por el nivel de colusión imperante en el país.

Palabras claves: incidencia, enmienda, constitución, auditoría de gestión, organizaciones públicas.

\section{ABSTRACT}

The management audit in the public sector examines the entities' activities through processes that assess the efficient use of its resources, reporting the results with recommendations for decision-making. The Constitution of 2008, Articles 211 and 212, defined that this action belongs to the comptroller's office. However, the Constitution was amended in 2015 by the Ecuadorian Assembly, to eliminate this action to avoid duplication of work between organizations. This study focuses on this problematic to determine its incidents, even though in 2018, the Constitutional Court declared its unconstitutionality, with judgment No. 18, published in 2019. The methods utilized in this study consist of the organization of materials, and their classification by sources and required documents, considering their relevance, completeness, and timeliness. Then the inductive-deductive, historical-logical, and analytical-synthetic methods were carried out to understand the causes and incidences compared to previous studies findings. The opposing legal impact on the control functions, because of the amendments, is the result of the work leaving 247 examinations in that period. The result was a discussion that demanded greater control from the management due to the general level of cooperation in the country.

Keywords: incidence, amendment, constitution, management audit, public organizations.

\section{INTRODUCCIÓN}

La Constitución es el instrumento legal que permite la organización de las diferentes leyes y normas que rigen las actividades internas y externas de un estado, legalmente reconocido por la Organización de las Naciones Unidas - ONU, basada en los preceptos de un sistema constitucional que tiene los mismos conceptos y lenguajes comunes generalmente aceptados.

Actualmente asistimos a la época de la internacionalización del derecho constitucional como consecuencia de los procesos de integración mundial, regional y subregional, así como, de convergencias entre países con iguales modelos y sistemas de desarrollo, empujados por los efectos de la globalización de la economía; por lo que, se observa una teoría constitucional común ajustada a las visiones políticas de sus actores más representativos que orientan a los miembros de la sociedad.

Los asuntos constitucionales nacieron de los hechos históricos y políticos de la sociedad organizada, que ha servido para relievar los procesos sociales coyunturales vividos que aleccionaron su futuro, los cuales surgieron con las diferentes culturas y naciones del mundo en la edad media y contemporánea, con cimientos de universalidad para impulsar el constitucionalismo democrático y de libre determinación de los pueblos, limitar el poder de los gobiernos o gobernantes y sobre todo, garantizar los derechos humanos.

En este marco se concibe una constitución, que generalmente nace de sus ciudadanos que la elaboran, la consensuan y la aprueban para su aplicación e implementación, la misma que luego puede ser modificada o enmendada para 
mejorarla con el mismo procedimiento o a través de sus representantes llamados senadores, diputados, asambleístas o legisladores, como comúnmente se los conoce.

La constitución del Ecuador no ha sido la excepción, nació en el 2008 con estos preceptos legales y sobre todo garantista de los derechos humanos y de la naturaleza para organizar el desarrollo sostenido en todos sus ámbitos.

La gestión de las entidades, sean estas públicas o privadas actualmente están siendo exigidas por los desafíos del mundo moderno de la producción de bienes y servicios para satisfacer las necesidades de los individuos; en este contexto, se requiere establecer claramente los objetivos, metas y estrategias que permitan lograr bienestar para los servidores y servidos en el marco de una estructura organizativa que tenga una misión y visión bien definida, que solo se logra concibiendo planes a corto, mediano y largo plazo.

Por lo que la administración de una entidad moderna debe desarrollar una cultura de planificación estratégica de todas sus actividades y proyectos, con eficiencia, eficacia y efectividad en el uso de sus recursos, para lograr el máximo rendimiento y satisfacción, a través de un buen sistema de gestión y operación con un estricto régimen de monitoreo, control y evaluación, determinando los indicadores de gestión ajustados a su realidad para la toma de decisiones.

Por las razones anteriores nació la auditoría de gestión en estas entidades, para examinar el trabajo de los hechos pasados como elemento básico para conocer la realidad del manejo económico de sus recursos, misma que la realiza un Auditor Profesional que al final emite un informe que contiene todo su proceso con conclusiones y recomendaciones.

En Ecuador, así concebida, se aplica en todas las entidades a excepción del sector público, porque desde el 2015 con una enmienda constitucional aprobada por la Asamblea Nacional, se le quitó a la Contraloría General del Estado esta potestad que estaba consagrada en esta constitución, para evitar duplicidad de funciones entre organismos públicos; aunque en agosto de 2018 la Corte Constitucional con sentencia No 18 las declaró inconstitucional, la que fue publicada en el registro oficial No 79 el 30 de abril de 2019.

Las entidades públicas son todas las instituciones establecidas por el Estado para cumplir con su rol de ejecutar, controlar y supervisar todas las actividades de la sociedad en el marco de su competencia; creadas desde tiempos muy remotos a la sombra de las teorías: institucional y capacidades dinámicas, desde una perspectiva sociológica, considerando el comportamiento humano como decidor del desarrollo social.

En este contexto se puede observar a las organizaciones como los entes gubernamentales que tienen la capacidad para adaptarse a cualquier circunstancia que demande el entorno en el que se desenvuelve, con el objetivo de satisfacer sus necesidades de manera individual o en cooperación con otras entidades públicas 0 privadas.

Estas entidades tienen la capacidad de ligar elementos colaterales y parecidos, y ordenar sus relaciones de coexistencia pacífica en la ejecución de las actividades y procesos requeridos para satisfacer las necesidades más sentidas de la población; dinamizando así la gobernanza como el proceso fundamental de la función pública del estado.

Bajo estas concepciones, el Ecuador tiene organizado el sector público con todas sus entidades adscritas a la función ejecutiva, legislativa y judicial, así como, con una fuerte desconcentración de las entidades de los gobiernos autónomos provinciales, 
cantonales y parroquiales; mismas que por disposiciones constitucionales y legales tienen que planificar sus actividades a largo, mediano y corto plazo, para lograr los objetivos del estado y presupuestando permanentemente el origen y uso de los recursos públicos, que deben ser controlados y fiscalizados por los organismos públicos de control correspondientes, como la Contraloría General del Estado.

Ante el problema presentado en el país por la falta de control a la gestión en estas entidades, como consecuencia de la eliminación de competencias a la primera entidad de control, a través de las Enmiendas Constitucionales del 2015, nace esta investigación para conocer la realidad del problema, así como conocer el resultado provocado por la no ejecución de estas auditorías producto de las enmiendas. El objetivo planteado fue conocer la incidencia de las Enmiendas Constitucionales en la ejecución de la auditoría a la gestión por parte de la Contraloría a las entidades públicas ecuatorianas; para lo cual se analizarán los conceptos más importantes como la Constitución y el Constitucionalismo, Enmiendas constitucionales, Auditoría y Auditoría de gestión, Organizaciones públicas y Organizaciones públicas de control, Organizaciones de control en el Ecuador, Contraloría General del Estado del Ecuador, Enmiendas constitucionales a las normas de la Contraloría General del Estado del Ecuador y la Declaratoria de la Inconstitucional de las mismas por parte de la Corte Constitucional del Ecuador.

También se analizó toda la documentación existente sobre estas Enmiendas, aunque hay que reconocer que se ha escrito muy poco sobre este tema desde el punto de vista de la auditoría; la información obtenida se contrastó con las resoluciones tomadas por los diferentes organismos sobre la vigencia de las mismas y la incidencia en el control de la gestión de los organismos públicos y privados que administren recursos de la potestad estatal producto de las enmiendas por parte de la Contraloría, así como con la experiencia de los autores en relación con el tema desde el punto de vista de la Auditoría de Gestión, empleando los métodos empíricos de investigación científica para describir y explicar la realidad, así como para recabar, resumir e interpretar sus resultados.

\section{Fundamentación}

Como marco teórico de esta investigación se profundizará teorizando los conceptos más importantes del problema planteado que permita comprender su realidad y proponer alternativas de solución:

\section{a. Lineamientos conceptuales sobre la Constitución y el Constitucionalismo}

Según la Universidad Nacional Autónoma de México - UNAM (2016), para hablar de constitución se debe relacionar los conceptos constitucionalismo y teoría de la constitución en sus significados teórico e histórico, en donde la Constitución es la ley fundamental de un país, a partir de la cual, se organiza y se desenvuelve un sistema de normas en el que se otorga a las personas o a un grupo de personas una serie de derechos y responsabilidades, organizando así el poder social, económico, político y cultural de un país.

Con lo que los autores sin ser entendidos en asuntos constitucionales y legales están de acuerdo porque conocen cómo funcionan los derechos y deberes constitucionales al interior de una sociedad como la ecuatoriana, que tiene una organización de Estado Presidencialista, con tres funciones principales con los mismos niveles de autoridad y responsabilidad, que son: la Ejecutiva, representada por el Presidente de la República con todos sus Ministerios o Secretarías de estado e instituciones adscritas; la Legislativa, conformada por la Asamblea nacional con todos sus Asambleístas nacionales, provinciales, de migrantes y andinos; y la Judicial, 
con su Consejo de la judicatura, Corte constitucional, Corte suprema de justicia, Cortes superiores provinciales, Juzgados de los diferentes procesos legales y demás dependencias.

Según Díaz (2018), el significado histórico del constitucionalismo señala que el término Constitución posee un sentido y valor fundamentalmente histórico, producto de la evolución manifestada en los diversos textos constitucionales, los que ofrecen un legado que se resume en las ideas garantistas de los derechos, la separación de poderes sintetizados en el Estado de derechos y el principio democrático, así como el valor de la constitución como norma suprema.

Lo que compartimos, porque las constituciones más modernas como la ecuatoriana es garantista de los derechos de los ciudadanos, de la naturaleza y de los derechos humanos, así como su declaración de la separación de funciones para lograr la gobernabilidad de la sociedad; tanto así, que en el Art. 1 de la Constitución del 2008 vigente expresa, que el Ecuador es un Estado constitucional de derechos y justicia: social, democrático, soberano, independiente, unitario, intercultural, plurinacional y laico; se organiza como República y se gobierna de manera descentralizada; la soberanía radica en el pueblo, cuya voluntad es el fundamento de la autoridad y se ejerce a través de los órganos del poder público y de las formas de participación directa previstas en la constitución; los recursos naturales no renovables del territorio del estado pertenecen a su patrimonio inalienable, irrenunciable e imprescriptible.

\section{b. Concepciones de la Enmienda Constitucional}

La Enmienda constitucional según Palomino (2018), es el dogma o la teoría constitucional que sin duda alguna, es el mejor recetario y soporte para desarrollar una verdadera reforma constitucional; que concibe y diferencia la mutación y la enmienda constitucional como procedimientos, indicando que, según la Real Academia Española (2001), el vocablo Reforma equivale a la acción y efecto de reformar o reformarse, y el de Reformar significa volver a formar, rehacer, modificar algo, con la intención de mejorarlo; mientras que, Mutación significa acción y efecto de mudar o mudarse; y que Enmienda equivale a la acción y efecto de enmendar, propuesta de variante, adición o reemplazo de un proyecto, dictamen, informe, documento análogo.

Con lo que compartimos, porque esa es la concepción correcta de este procedimiento parlamentario; aunque las enmiendas constitucionales realizadas por la Asamblea nacional en el Ecuador en el 2015, tuvieron como finalidad según los asambleístas corregir errores literales y gramaticales en la redacción original de la Constitución del 2008, para evitar malas interpretaciones y duplicidad de funciones entre organismos públicos; y en el caso específico del Art. 211 y 212 de la responsabilidad y funciones de la Contraloría General del Estado, fue una supresión y suplantación de oraciones y términos relacionados con la potestad de medir el logro de objetivos de la gestión en las entidades públicas; eliminando y reemplazando así parte de sus enunciados en lo relacionado con la capacidad de esta entidad para ejecutar el control a la gestión en todos los organismos del sector público.

Las Enmiendas constitucionales según Redondo (2001), explica que el derecho parlamentario no revela diferencia entre la Iniciativa legislativa y la Enmienda, pero concibe a la enmienda como una iniciativa menor, o como una pseudopropuesta 0 simplemente como el corolario de una iniciativa; aunque estos instrumentos son distintos y su diferencia radica en la finalidad a la que responden uno u otro 
procedimiento de participación, para lo que hay que profundizar en sus orígenes, pese a que coinciden en el tiempo de aparecimiento.

La facultad de proponer alternativas y modificaciones a los textos de estas iniciativas es similar a la discusión parlamentaria actual, que se somete a las normas y rutinas legislativas; los parlamentos en donde no se admite el derecho de enmienda, se los consideran asambleas representativas pero no democráticas; aunque por primera vez en la historia parlamentaria española, se introdujo el concepto enmienda en el Reglamento del congreso de 1838.

Anteriormente los diputados se limitaban a discutir y votar las iniciativas del monarca, pero no tenían el derecho de modificar los textos; como el artículo 34 de la Constitución francesa de 1799, que negaba a los parlamentarios la capacidad de discusión y enmienda, pero su colaboración consistía en votar el proyecto tal y como era entregado.

La iniciativa y la enmienda se diferencian también en función de los fines que persiguen; la iniciativa es uno de los principales procedimientos con los que cuenta un Ejecutivo para impulsar su política y sacar adelante sus promesas electorales; mientras la capacidad de presentar enmiendas resulta ser un elemento que equilibra el poder del Ejecutivo en la elaboración de leyes, permitiendo a los parlamentarios ejercer la función legislativa que constitucionalmente les corresponde para enmendar todo lo que no esté bien; por lo tanto, a través de enmiendas los representantes colaboran en la formación de la ley y al mismo tiempo plantean sus propuestas y alternativas, sin olvidar que con las enmiendas la mayoría puede controlar y modificar las iniciativas que se someten a discusión.

En resumen, para los autores, las enmiendas son un control político parlamentario que se utiliza para modificar o suprimir toda iniciativa de ley que proponga el ejecutivo, en lo que los legisladores consideren que no están de acuerdo, porque a su criterio no resuelven los problemas de la sociedad. En el caso ecuatoriano, las enmiendas constitucionales de la Asamblea Nacional del Ecuador de diciembre de 2015 según Ediciones Legales (2016), no se realizaron sobre la base de una iniciativa del Ejecutivo, sino por iniciativa propia de los Asambleístas que les otorga el artículo 441 de la Constitución del 2008 que indica, que la enmienda de uno o varios artículos de la Constitución que no altere su estructura fundamental, o el carácter y elementos constitutivos del Estado, que no establezca restricciones a los derechos y garantías, o que no modifique el procedimiento de reforma de la Constitución, se realizará:

1. Mediante referéndum solicitado por la Presidenta o Presidente de la República, o por la ciudadanía con el respaldo de al menos el ocho por ciento de las personas inscritas en el registro electoral.

2. Por iniciativa de un número no inferior a la tercera parte de los miembros de la Asamblea Nacional.

El proyecto se tramitará en dos debates; el segundo debate se realizará de modo impostergable en los treinta días siguientes al año de realizado el primero. La reforma sólo se aprobará si obtiene el respaldo de las dos terceras partes de los miembros de la Asamblea Nacional.

\section{c. Definiciones de Auditoría y de Auditoria de Gestión}

La Auditoría según Manrique (2019), es un proceso sistemático para obtener y evaluar evidencias de manera objetiva, que se aplica en distintas actividades de una organización social como empresas privadas y públicas, entidades de otros sectores, ámbito fiscal, operacional, medioambiental, forense e informático; distinguiendo así a 
las auditorias tributaria, financiera, administrativa 0 de gestión, operativa, gubernamental, ambiental, académica y forense.

Fundamento con el que nos identificamos, porque la auditoría de manera general es el examen que se le realiza a cualquier entidad, empresa o negocio con el objetivo de conocer si sus actividades administrativas y operativas, económicas y financieras se realizan apegadas a las normas de control vigentes, lo que se conoce al finalizar el trabajo con la emisión de un informe que contiene todo su proceso así como con conclusiones y recomendaciones para la toma de decisiones correctivas y de mejora

La Auditoría de gestión según Vásquez y Pinargote (2018), es una herramienta de mejoramiento continuo para las organizaciones, porque con su aplicación se evalúa el cumplimiento de metas y objetivos a través de procesos de efectividad, eficiencia y eficacia; por lo que, en toda organización sus directivos la deben considerar, porque es una herramienta de mejoramiento permanente que garantiza la calidad exigida por la globalidad de economía actual.

Criterio que compartimos, porque la Auditoría de gestión también llamada Auditoría administrativa, es la evaluación indisoluble que se le realiza a las actividades administrativas y operativas de una organización sea esta pública o privada, para conocer el uso eficiente, efectivo y eficaz de sus recursos, basado en la gestión de las mismos a través de los sistemas de planificación y programación para el logro de sus objetivos institucionales, midiendo sus alcances con indicadores de gestión definidos para el efecto; actividad realizada por un Auditor profesional que al final de su trabajo emite un informe con todo el proceso ejecutado con conclusiones y recomendaciones para la toma de decisiones directivas.

\section{d. Las Organizaciones Públicas y Las Organizaciones Públicas de Control}

Las Organizaciones públicas según Ramió (2012), expresa que las Administraciones públicas son organizaciones a las que les corresponden satisfacer las necesidades de la comunidad; por lo que cualquier Administración pública es una organización, así como las entidades que forman parte de la misma, sean éstas independientes como agencias, organismos autónomos o empresas públicas, 0 dependientes como departamentos centrales; aunque su entorno esté configurado por otras unidades administrativas y que sus objetivos y decisiones estén condicionadas por instancias superiores; como una Municipalidad, que es una organización pública pero con sus unidades administrativas diferenciadas formalmente como independientes o no; que pueden ser consideradas como si fueran organizaciones con entidad propia, ya que poseen todos los elementos que caracterizan a una organización.

Con lo que estamos de acuerdo, porque a las administraciones públicas en la actualidad, también se las conoce como Organismos públicos, sean estos pequeños, medianos o grandes independientes o dependientes según sea el caso. También hay que indicar, que a éstas se diferencian de las privadas, nombrándolas como entidades u organismos públicos y a las otras como empresas, aunque la modernidad ha incorporado en los últimos tiempos la figura de las Empresas Públicas - EP que son las entidades públicas productivas, con normas de funcionamiento como empresas privadas, porque intervienen en el mercado con productos que también pueden ser producidos por la empresa privada.

Las Organizaciones públicas de control según Aguilar (2007), asegura que el control es una de las funciones propias del Estado, lo ejercen de una u otra manera, todas las instituciones que lo conforman, especialmente para regular las actividades privadas con la emisión de las normas que correspondan, aunque resulten 
insuficientes si no viene acompañadas de funciones de control, que aseguren el cumplimiento de esas normas, según lo afirma Sayagués (1986).

Los investigadores asentimos lo expresado, porque todas las naciones del mundo cuentan con muchos organismos de control, que permiten que todas las actividades de la sociedad se realicen en el marco de las normas estatuidas para la convivencia pacífica y la honradez en el manejo de sus recurso; estos organismos son muy diversos dependiendo del país y de su sistema de gobierno, pero se identifican entidades $u$ organismos de control en lo electoral, social, militar, constitucional, policial, justicia, legislativo, administrativo, recursos, empresarial, bancario, seguro, cooperativo, educativo, salud, ambiente.

La fundamentación teórica antes descrita permite abordar el problema del tema de esta investigación, para lo cual es necesario analizar lo siguiente:

\section{Los Organismos Públicos de Control en el Ecuador}

Los Organismos públicos de control en el Ecuador según la Asamblea Nacional del Ecuador (2008), se reconocen en la Constitución vigente en su Título IV Participación y Organización del Poder, Capítulo Quinto, Función de las Entidades de Transparencia y Control Social, Sección Primera Naturaleza y Funciones, Art. 204, diciendo que el pueblo es el mandante y primer fiscalizador del poder público, en ejercicio de su derecho a la participación. La Función de Transparencia y Control Social promoverá e impulsará el control de las entidades y organismos del sector público, y de las personas naturales o jurídicas del sector privado que presten servicios o desarrollen actividades de interés público, para que los realicen con responsabilidad, transparencia y equidad; fomentará e incentivará la participación ciudadana; protegerá el ejercicio y cumplimiento de los derechos; y prevendrá y combatirá la corrupción. La Función de Transparencia y Control Social estará formada por el Consejo de Participación Ciudadana y Control Social, la Defensoría del Pueblo, la Contraloría General del Estado y las Superintendencias. Estas entidades tendrán personalidad jurídica y autonomía administrativa, financiera, presupuestaria y organizativa.

Según la Función de Transparencia y Control Social (2019), en su Plan nacional de integridad pública y lucha contra la corrupción 2019-2023, esta función la conforman los siguientes organismos públicos de control: Contraloría General del Estado; Superintendencia de Control del Poder de Mercado; Consejo de Participación Ciudadana y Control Social; Superintendencia de Economía Popular y Solidaria; Superintendencia de Compañías, Valores y Seguros; Superintendencia de Bancos; Defensoría del Pueblo; Superintendencia de Ordenamiento Territorial, Uso y Gestión del Suelo; Superintendencia de la Información y Comunicación; y la Secretaria Técnica del Comité de Coordinación de la Función de Transparencia y Control Social.

Por lo antes indicado, el sistema de control público en el Ecuador, se ejecuta a través de esta función del Estado, que está conformada por las entidades y organismos antes mencionados, pero del cual, no forma parte la Secretaría Nacional de la Administración Pública, que según los asambleístas en sus argumentos de enmienda, era la función encargada de realizar el control a la gestión en las entidades y organismos públicos.

Según el Instituto Nacional Estadísticas y Censos - INEC (2012), la Secretaría Nacional de la Administración Pública - SNAP es una de las oficinas integrales de la Presidencia de la República, misma que en los Art. 13 y 14 Organización de la Función Ejecutiva, publicado en el Registro Oficial No 536, del lunes 18 de marzo de 2002, el Secretario General de la Administración Pública asesora y asiste al Presidente de la 
República en la adopción y ejecución de las políticas generales del Estado, para lo cual coordina y realiza las gestiones que se requiera con los ministros de Estado y demás funcionarios del sector público; por lo que corresponde a esta Secretaría el despacho de los asuntos administrativos de la Presidencia.

Las funciones expuestas anteriormente, permiten ratificar que este organismo no tiene competencia para realizar el control a la gestión en las entidades y organismos del sector público como se afirmaba.

\section{La Contraloría General del Estado del Ecuador.}

En la referida Constitución de los Organismos públicos de control en el Ecuador del tema anterior, en el Título y Capítulo descrito y en la Sección tercera se reconoce a la Contraloría General del Estado como una de las entidades de control, según el Art. 211 ésta es un organismo técnico encargado del control de la utilización de los recursos estatales, y la consecución de los objetivos de las instituciones del Estado y de las personas jurídicas de derecho privado que dispongan de recursos públicos, y el Art. 212 serán funciones de este Organismo, además de las que determine la ley:

- Dirigir el sistema de control administrativo que se compone de auditoría interna, auditoría externa y del control interno de las entidades del sector público y de las entidades privadas que dispongan de recursos públicos.

- Determinar responsabilidades administrativas y civiles culposas e indicios de responsabilidad penal, relacionadas con los aspectos y gestiones sujetas a su control, sin perjuicio de las funciones que en esta materia sean propias de la Fiscalía General del Estado.

- Expedir la normativa para el cumplimiento de sus funciones.

4. Asesorar a los órganos y entidades del Estado cuando se le solicite.

Disposiciones legales que confirman la función de control que tiene la Contraloría sobre todos los recursos que administran las entidades públicas y las empresas u organizaciones privadas, que hayan recibido o reciban recursos del Estado para ejecutar sus actividades de producción o servicios en beneficio de la comunidad.

\section{Las Enmiendas constitucionales a las normas de la Contraloría General del Estado del Ecuador.}

Las enmiendas constitucionales a las normas de la Contraloría según Ediciones Legales (2016), se realizaron en sesión del 3 de diciembre de 2015, el Pleno de la Asamblea Nacional del Ecuador aprobó las Enmiendas Constitucionales; considerando que, el artículo 441 de la Constitución de la República prescribe que se puede realizar la enmienda de uno o varios artículos de la Constitución cuando no se altere su estructura fundamental, el carácter y elementos constitutivos del Estado, no se establezca restricciones a los derechos y garantías y no se modifique el procedimiento de reforma de la Constitución; que de conformidad con este artículo para la aprobación de la enmienda se requiere el respaldo de las dos terceras partes de los miembros de la Asamblea Nacional; y, en uso de sus atribuciones constitucionales y legales, aprueba las Enmiendas a la Constitución de la República del Ecuador; mismas que en lo relacionado con la responsabilidad y funciones de la Contraloría General del Estado, fueron: Art. 6, en el artículo 211, suprímase la frase", y la consecución de los objetivos de las instituciones del Estado", y Art. 7, en el artículo 212 numeral 2, suprímanse las palabras "y gestiones" y sustitúyase la palabra "sujetas" por "sujetos"; dado en Quito, Provincia de Pichincha, en la Sala de Sesiones del Pleno de la Asamblea Nacional.

Esta disposición mutila o cercena las competencias que tenía la Contraloría para controlar la gestión de las máximas autoridades de las entidades públicas, midiendo 
el uso de los recursos públicos con indicadores resultantes de la ejecución de planes, programas y proyectos, dirigidos a la consecución de los objetivos del estado.

\section{La Declaratoria de inconstitucionalidad de las enmiendas}

La Declaratoria de inconstitucionalidad de las enmiendas de 2015 a la Constitución según LEXISFINDER (2019), fue realizada por la Corte Constitucional del Ecuador con Resolución No 18 del 2 de agosto de 2018 y publicada en el Registro oficial edición constitucional No 79 del 30 abril de 2019, considerando que personas naturales, organizaciones sociales y movimientos políticos presentaron una demanda de acción pública de inconstitucionalidad en contra de las Enmiendas a la Constitución de la República del Ecuador, aprobadas por la Asamblea Nacional el 3 de diciembre de 2015 y promulgadas en el Suplemento del registro oficial No 653 de 21 de diciembre de 2015, con los siguientes elementos:

- Aceptar las demandas de acción pública de inconstitucionalidad No 0102-15-in, 0006-16-in y 0008-16-in.

- Negar las demandas de acción pública de inconstitucionalidad Nos 099-15-in, 0100-15-in, 001-16-in, 002-16-in, 003-16-in, 004-16-in y 005-16-in.

- En ejercicio de la facultad consagrada en el artículo 436 numerales 1 y 2 de la Constitución de la República, en concordancia con el artículo 76 numerales 4, 5 y 6 de la Ley orgánica de garantías jurisdiccionales y control constitucional, se declara la Inconstitucionalidad por la forma de las Enmiendas a la Constitución de la República del Ecuador, aprobadas por la Asamblea Nacional del ecuador el 3 de diciembre de 2015, a excepción de las enmiendas constantes en los artículos 2 y 4 que modificaron los artículos 114 y 144 de la Constitución de la República, en virtud de que fueron derogadas por efecto de la promulgación de los Resultados del Referéndum y la Consulta popular efectuados el día 4 de febrero de 2018, en el Suplemento del registro oficial No 180 de 14 de febrero de 2018.

Esta resolución legal a partir de su publicación, devuelve en el caso de la Contraloría General del Estado la potestad de ejecutar las Auditorías de Gestión, al uso de los recursos públicos por parte de los Organismos públicos y privados que administren recursos del estado, para conocer la calidad del gasto e inversión ajustada a la eficiencia, eficacia y efectividad de los planes y programas y proyectos elaborados y ejecutados para el efecto; medidos con indicadores de gestión propio de estas actividades, en beneficio de la sociedad para lograr el desarrollo del país.

\section{METODOLOGÍA}

La metodología utilizada en este trabajo representó la serie de métodos y técnicas de rigor científico que se aplicaron sistemáticamente durante el proceso de la investigación para alcanzar el resultado teórico válido, que permitió comprender la realidad del problema, analizar sus consecuencias y determinar su incidencia con resultados concretos, los mismos que fueron:

1. Los Métodos utilizados para ejecutar esta obra de investigación científica según Cabezas, Andrade, y Torres (2018), fueron:

Inductivo-Deductivo. Para inducir y deducir los hechos de las actividades de las Enmiendas constitucionales desde su contexto general hasta sus particularidades y viceversa, que a partir de la bibliografía analizada trasladarse desde el conocimiento objeto de estudio a la comprensión de sus efectos en las actividades del control de las entidades públicas y privadas que administran recursos del Estado. 
Histórico-Lógico. Para investigar la historia, fundamentos, elementos y proceso de las Enmiendas constitucionales, para comprender los principios y condiciones en las que se desarrollaron.

Analítico-Sintético. Para detallar de manera concreta los elementos relacionadas con las Enmiendas constitucionales, manifestados en el problema investigado.

Cualitativo-Cuantitativo. Para recolectar los datos relacionados con las Enmiendas constitucionales y sus efectos con o sin medición numérica, para realizar los análisis requeridos e interpretar sus resultados.

La aplicación de estos métodos en la investigación permitieron conocer la realidad del problema investigado, estableciendo las causas que provocan los problemas y lograr conocer los resultados de la no aplicación de las auditorías de gestión por parte de la Contraloría General del estado por la aprobación de las Enmiendas constitucionales.

2. La teorización del problema analizado se basó en la investigación bibliográfica documental que según Rodríguez (2013), es el proceso sistemático de recolección, selección, clasificación, evaluación y análisis de contenidos del material empírico impreso y gráfico, físico y virtual, que sirvió de fuente teórica de información conceptual y metodológica para esta labor; lo que permitió conocer su realidad, estableciendo las causas que provocaron el problema y los resultados de la aplicación de las Enmiendas constitucionales que no permitieron ejecutar las Auditorías de gestión a la Contraloría.

Según esta misma fuente, los Materiales utilizados en la investigación para la recolección, procesamiento y análisis de la información, en primer lugar fueron todos los datos teóricos y técnicos consultados, que se realizó considerando primeramente el objetivo de la investigación, definiendo los tipos de fuentes bibliográficas y los documentos requeridos; $y$ en segundo lugar las fuentes bibliográficas y documentales, se definieron y se clasificaron de acuerdo a los criterios de selección que se necesitaban, los mismos que fueron:

De pertinencia. Que las fuentes consultadas estuvieran en concordancia con el objetivo de la investigación, aportando conocimientos, enfoques, teorías, conceptos y experiencias significativas para fundamentar la investigación;

De exhaustividad. Que las fuentes consultadas fueran la mayor cantidad posibles, necesarias y suficientes para fundamentar el trabajo, sin exclusiones y permitiendo su enumeración y clasificación; y

De actualidad. Que las fuentes consultadas fueran actuales para asegurar información de último tiempo, con recientes hallazgos y antecedentes empíricos pertinentes, referidos a sucesos del pasado reciente.

Con estos procedimientos de trabajo teóricos y prácticos, se fundamentó la investigación, se analizó profundamente el problema y se determinaron los resultados producto de sus incidencias.

\section{RESULTADOS Y DISCUCIÓN}

Los resultados de esta investigación están íntimamente ligados a las Incidencias de las Enmiendas constitucionales en la Auditaría a la gestión de las entidades públicas ecuatorianas, que correspondían según la Constitución del 2008 a la Contraloría General del Estado y su discusión sometida a la poca información escrita sobre los efectos de estas Enmiendas en lo relacionado con la Auditoría de gestión, los mismos que son: 
1. Impacto legal negativo de las Enmiendas constitucionales. Para mayor comprensión de los impactos legales de estas enmiendas en la responsabilidad y las funciones de este Organismo de control, se presenta la Tabla 1:

Tabla 1:

Comparativo de la responsabilidad y las funciones de la Contraloría entre la Constitución y las Enmiendas

\begin{tabular}{|c|c|c|}
\hline $\begin{array}{l}\text { Parte afectada del } \\
\text { contenido de los artículos } \\
\text { de la constitución de } 2008\end{array}$ & 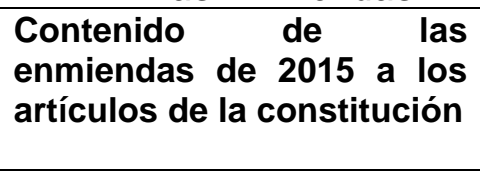 & $\begin{array}{l}\text { Parte afectada del } \\
\text { contenido de los artículos } \\
\text { de la constitución luego de } \\
\text { las enmiendas }\end{array}$ \\
\hline $\begin{array}{l}\text { Art. 211.- La Contraloría } \\
\text { General del Estado es un } \\
\text { organismo técnico encargado } \\
\text { del control de la utilización de } \\
\text { los recursos estatales, y la } \\
\text { consecución de los objetivos } \\
\text { de las instituciones del } \\
\text { Estado y de las personas } \\
\text { jurídicas de derecho privado } \\
\text { que dispongan de recursos } \\
\text { públicos. } \\
\text { Art. } 212 .- \text { Serán funciones de } \\
\text { la Contraloría General del } \\
\text { Estado, además de las que } \\
\text { determine la ley: } \\
2 . \quad \text { Determinar } \\
\text { responsabilidades } \\
\text { administrativas y civiles } \\
\text { culposas e indicios de } \\
\text { responsabilidad penal, } \\
\text { relacionadas con los } \\
\text { aspectos y gestiones sujetas } \\
\text { a su control, sin perjuicio de } \\
\text { las funciones que en esta } \\
\text { materia sean propias de la } \\
\text { Fiscalía General del Estado. }\end{array}$ & $\begin{array}{l}\text { Art. 7.- En el artículo } 212 \\
\text { numeral 2, suprímanse las } \\
\text { palabras "y gestiones" y } \\
\text { sustitúyase la palabra } \\
\text { "sujetas" por "sujetos". }\end{array}$ & $\begin{array}{l}\text { Art. 212.- Serán funciones de } \\
\text { la Contraloría General del } \\
\text { Estado, además de las que } \\
\text { determine la ley: } \\
2 . \\
\text { responsabilidades Determinar } \\
\text { administrativas y civiles } \\
\text { culposas e indicios de } \\
\text { responsabilidad penal, } \\
\text { relacionadas con los } \\
\text { aspectos sujetos a su control, } \\
\text { sin perjuicio de las funciones } \\
\text { que en esta materia sean } \\
\text { propias de la fiscalía general } \\
\text { del Estado. }\end{array}$ \\
\hline
\end{tabular}

Elaborado por: Elaboración propia

El contenido legal de la responsabilidad y las funciones constitucionales de la Contraloría, resultante de la aplicación de las Enmiendas constitucionales aprobadas por la Asamblea desde diciembre de 2015, que eliminaron y sustituyeron oraciones y palabras en la redacción de los Art. 211 y 212 de la Constitución de 208, impactaron negativamente en la responsabilidad y funciones de este Organismo, porque excluyeron de su acción legal de control, la ejecución de las Auditorías de gestión a las entidades y organismos públicos y a las empresas privadas que administraron recursos del Estado en el período que estuvieron vigentes.

Discutiendo este resultado, se revela la acuciosidad con la que se eliminaron y sustituyeron oraciones y palabras con las Enmiendas, a las disposiciones de las funciones constitucionales de la Contraloría, hace pensar que se hicieron para evitar que la primera entidad de control del país, ejecutara el control a la Gestión de los funcionarios y empleados públicos de las diferentes entidades; es decir, evitar que esta institución exigiera cuentas del uso de los recursos, midiéndolos con indicadores de gestión para determinar el grado de consecución de los objetivos del estado. 
En este análisis El Universo (2015), establece que, en los debates de las enmiendas, los Asambleístas interesados argumentaron que estas modificaciones buscaban evitar la duplicidad de funciones entre la Contraloría y otros órganos del poder público y lograr eficiencia en la administración pública. De igual manera, en el segundo debate en la Comisión ocasional de enmiendas, se argumentó que la Secretaría de la Administración Pública, era la función encargada de realizar el control de la Gestión de las entidades u organismos de la función ejecutiva, para la consecución de los objetivos de los planes, programas y proyectos; porque los productos del control de la gestión que realiza esta secretaría, son insumos para que el Presidente de la República rinda cuentas al país; así como de que el rol primigenio de la Contraloría es el de ser juez de cuentas.

2. Auditorías de gestión ejecutadas. Según El Universo (2015), por declaraciones del Contralor Carlos Polit, entre el 2007 y el 2014 la Contraloría General del Estado ejecutó 433 Auditorías de gestión que abarcaron áreas de servicios de salud, sistemas de recursos humanos, riego, informáticos y otros sectores; con lo que mejoró la calidad del gasto en estas entidades, optimizando la utilización de los recursos públicos en beneficio del país y de las comunidades de las entidades auditadas.

En la discusión de este resultado, la fuente antes indicada, señalaba también que el Contralor de la época manifestó su desacuerdo con la iniciativa y la aprobación del proyecto de las Enmiendas, reiterando que era antitécnico porque en todo examen que realiza la Contraloría el componente de gestión es un factor que está presente, de manera indisoluble, por la razón de que el control de los recursos públicos es un sistema y no un conjunto aislado de actividades.

3. Auditorías de gestión que se dejaron de ejecutar. Si consideramos que del 2015 hasta el 2019 que estuvieron vigentes las Enmiendas, declaradas inconstitucionales en este último año, fueron 4 años que no se ejecutaron las Auditorías de gestión por parte de la Contraloría, en relación con el resultado anterior, sería el 57,14\% que no se ejecutaron en este periodo, representando 247 exámenes que se dejaron de hacer, a las diferentes entidades públicas y a las organizaciones privadas que administraron fondos públicos, producto de la supresión de las normas señaladas anteriormente; permitiendo así el aumento de casos de colusión en la mayoría de áreas de servicios y de dotación de infraestructura del Estado, que se tramitan en la justicia ordinaria por denuncias ciudadanas e iniciativas propias de la Fiscalía General del Estado.

Profundizando esta discusión, se ratifica que en este período que no se realizaron las auditorías a la gestión de las diferentes entidades públicas, dejándose de controlar el uso de los recursos; con lo que bien se habría controlado de mejor manera tanto casos de colusión que se conocen actualmente, muchos de ellos ya han sido sentenciados por los jueces y otros están en proceso de investigación por la justicia ordinaria; en el mismo sentido según Primicias (2021), en el caso de la fracasada construcción de la Refinería del Pacífico en el Aromo Manabí, que entre el 2011 y 2017 se le invirtieron USD 1.528 millones en nivelación y preparación del terreno y una escasa infraestructura, de los cuales la Contraloría ha emitido glosas solidarias por USD 1.223 millones por mal manejo de los recursos públicos, en octubre de 2020 luego de que terminó la auditoría a la gestión de ese proyecto; ratificando así la importancia de este tipo de auditoría en la gestión pública ecuatoriana. 


\section{CONCLUSIONES}

La Constitución de 2008 vigente en su Art. 204, reconoce a los Organismos de control en el Ecuador a aquellos que formen parte de la Función de Transparencia y Control Social, como la encargada de impulsar el control de las entidades y organismos del sector público, y de las personas naturales o jurídicas del sector privado que desarrollen actividades de interés público; misma que está conformada por el Consejo de Participación Ciudadana y Control Social, la Defensoría del Pueblo, la Contraloría General del Estado y las Superintendencias.

La referida Constitución en relación con la Contraloría en el Art. 211 indica, que ésta es un organismo técnico encargado del control de la utilización de los recursos estatales, y la consecución de los objetivos de las instituciones del Estado y de las personas jurídicas de derecho privado que dispongan de recursos públicos y el Art. 212 detallan cada una de las funciones del mismo; lo que le da potestad a esta entidad para auditar la gestión en las entidades públicas, cuando declara el control de los recursos y la consecución de objetivos, los que siempre ha estado atado a la preparación y ejecución de planes y proyectos institucionales.

Que las enmiendas constitucionales a las normas de la Contraloría, se realizó el 3 de diciembre de 2015 por el Pleno de la Asamblea Nacional del Ecuador, basado en el artículo 441 de la Constitución que permite que se puede realizar la enmienda de uno o varios artículos de la Constitución cuando no se altere su estructura, el carácter y elementos constitutivos del Estado, no se establezca restricciones a los derechos y garantías y no se modifique el procedimiento de reforma de la Constitución; con la aprobación de las dos terceras partes de sus miembros; disposición que mutila o cercena las competencias que tenía este Organismo para controlar la gestión de las autoridades de las entidades públicas, midiendo el uso de los recursos públicos con indicadores resultantes de la ejecución de planes y proyectos, dirigidos a la consecución de los objetivos del estado; aunque la Corte Constitucional del Ecuador con Resolución No 18 del 2 de agosto de 2018 y publicada en el Registro oficial No 79 del 30 abril de 2019, por demandas presentadas por personas naturales, organizaciones sociales y movimientos políticos; en ejercicio de la facultad consagrada en el artículo 436 numerales 1 y 2 de la Constitución y en concordancia con el artículo 76 numerales 4, 5 y 6 de la Ley orgánica de garantías jurisdiccionales y control constitucional, declaró su Inconstitucionalidad por la forma; Resolución que a partir de su publicación, devuelve a la Contraloría la potestad de ejecutar las Auditorías de gestión, al uso de los recursos por parte de los Organismos públicos y privados que administren recursos del Estado, para conocer la calidad del gasto e inversión ajustado a la eficiencia, eficacia y efectividad de los planes y proyectos elaborados y ejecutados para el efecto; medidos con indicadores de gestión para beneficio de la sociedad ecuatoriana.

Que las incidencias más importantes de las Enmiendas realizadas a las funciones constitucionales de la Contraloría fueron:

El impacto legal negativo de las enmiendas, que en el artículo 211, suprimió la frase ", y la consecución de los objetivos de las instituciones del Estado", y en el artículo 212 numeral 2, suprimió las palabras "y gestiones" y sustituida la palabra "sujetas" por "sujetos"; con lo que se dejó de ejecutar las auditorías de gestión en las entidades y organismos del sector público a partir de su aprobación el 3 de diciembre de 2015. 
Las auditorías de gestión realizadas, según el Contralor de la época entre el 2007 y el 2014, se ejecutaron 433 Auditorías que abarcaron servicios de salud, sistemas de recursos humanos, riego, informáticos y otros sectores, observándose mejoras en la calidad del uso de los recursos del estado, lo que justificaba la importancia de esta función en este Organismo de control para beneficio del país.

Las auditorías de gestión no realizadas, en el período de 4 años del 2015 al 2019 que estuvieron vigentes las Enmiendas, se hubieran podido realizar 247 Auditoría de este tipo en relación con las ejecutadas del párrafo anterior, pese a su Declaratoria de Inconstitucionalidad realizada en el 2018 y publicada en el 2019 por la Corte Constitucional por mala votación de los miembros de la Asamblea, devolviendo así a este Organismo de control toda su responsabilidad y funciones; con lo que se habría controlado mejor tanto casos de colusión que actualmente se ventilan en la justicia ordinaria, relacionados con: servicios y construcciones hospitalarias, educativas, eléctricas, deportivas, petroleras, caminos y carreteras, puertos y aeropuertos, entre otras áreas importantes.

\section{REFERENCIAS BIBLIOGRÁFICAS}

Aguilar, J. (2007). Compromiso político y organismos de control. FORO revisto de derecho, No. 7, UASB-Ecuador / CEN • Quito, 2007. Recuperado el 2 de julio de 2021. de file:///C:/Users/HP/AppData/Local/Temp/324Texto\%20del\%20art\%C3\%ADculo-1254-1-10-20170118.pdf

Asamblea Nacional del Ecuador (ANE). (2008). Constitución de la República del Ecuador. Decreto Legislativo 0. Publicación: Registro Oficial 449 de 20 de octubre de 2008.

Cabezas, E., Andrade, D. y Torres, J. (2018). Introducción a la metodología de la investigación científica. Primera edición electrónica. Octubre de 2018. Universidad de las Fuerzas Armadas ESPE. ISBN: 978-9942-765-44-4. Ecuador.

Díaz, F. (2018). Fundamentos actuales para una teoría de la Constitución. Instituto de Estudios Constitucionales del Estado de Querétaro México.

Ediciones Legales. (2016). Enmiendas a la Constitución de la República del Ecuador. Enmienda S/N. Suplemento del Registro Oficial 653 del 21de diciembre de 2015.

El Universo. (2015). Noticia Contraloría ya no auditará la gestión de entidades públicas. 9 de diciembre, 2015. Recuperado el 9 de junio de 2021 de https://www.eluniverso.com/noticias/2015/12/09/nota/5287731/contraloria-yano-auditara-gestion-entidades-publicas/

Función de Transparencia y Control Social - FTCS. (2019). Plan Nacional de Integridad Pública y Lucha contra la Corrupción. 2019-2023. Pág. 5. Recuperado el 6 de agosto de 2021 de https://www.contraloria.gob.ec/WFDescarga.aspx?id=2629\&tipo=doc

Instituto Nacional Estadísticas y Censos - INEC. (2012). Objetivos de la Secretaría Nacional de la Administración Pública. 27 de octubre de 2012 - 10:52 am. Recuperado el 18 de agosto de 2021 de https://www.ecuadorencifras.gob.ec/objetivos/

LEXISFINDER. (2019). Declaratoria de inconstitucionalidad de enmiendas 2015 a la constitución. Resolución de la corte constitucional no 18. Registro oficial edición constitucional no 79 del 30 de abril de 2019. Estado vigente. 
Recuperado el 24 de agosto de 2021 de https://www.enamiep.gob.ec/wpcontent/uploads/downloads/2020/07/declaratoria-inconstitucionalidadenmiendas-2015.pdf

Manrique, J. (2019). Introducción a la auditoría. Editado por: Universidad Católica Los Ángeles de Chimbote. Perú. Primera edición digital, octubre 2019. ISBN: 978612-4308-14-7. Pág. 16

Palomino, J. (2018). ¿Reforma, mutación o enmienda constitucional? Instituto de Investigaciones Jurídicas - Universidad Nacional Autónoma de México Instituto Iberoamericano de Derecho Constitucional.

Primicias. (2021). Noticia. Contraloría: glosa de USD 1.223 millones por Refinería del Pacífico Economía. Redacción Primicias Actualizada: 13 May 2021 - 16:40. Recuperado el 6 de agosto de 2021 de https://www.primicias.ec/noticias/economia/contraloria-glosa-millonesrefineria-pacifico/

Ramió, C. (2012). Artículo Teoría de la Organización y Administración Pública. Pág. 1. Recuperado el 1 de julio de 2021 de https://tecnoadministracionpub.files.wordpress.com/2012/08/u1-carles-ramioteoria-de-la-organizacion.pdf

Real Academia Española. (2001). Diccionario de la Lengua Española, 22ava. Edición, Madrid, 2001. Recuperado el 18 de agosto de 2021 de https://www.rae.es/obras-academicas/diccionarios/diccionario-de-la-lenguaespanola-2001

Redondo, A. (2001). Artículo. El derecho de enmienda como instrumento de integración del pluralismo político en la fase central de los procedimientos legislativos de las cortes generales. Revista de Derecho Político, núm. 50, 2001, pp. 189-218.

Rodríguez, M. (2013). Investigación bibliográfica y documental. Recuperado el 20 de agosto de 2021 de https://guiadetesis.wordpress.com/2013/08/19/acerca-dela-investigacion-bibliografica-y-documental/

Sayagués, E. (1986). Tratado de Derecho Administrativo, tomo I, Montevideo, Martín Bianchi, 1986, pp. 52-55.

Universidad Nacional Autónoma de México - UNAM. (2016). El Constitucionalismo y la teoría de la Constitución. Instituto de Investigaciones Jurídicas. Secretaría de Cultura - Instituto Nacional de Estudios Históricos de las Revoluciones de México Senado de la República.

Vásquez, M. y Pinargote, N. (2018). Auditoría de gestión: una herramienta de mejora continua. Universidad Laica Eloy Alfaro de Manabí (ULEAM). ISBN: 978-9942775-51-1. 